\title{
ABRIGOS DE MOSQUITOS CULEX (CULEX) EM ZONA RURAL (DIPTERA: CULICIDAE)*
}

\author{
Almério de Castro Gomes** \\ Oswaldo Paulo Forattini**
}

GOMES, A. de C. \& FORATTINI, O. P. Abrigos de mosquitos Culex (Culex) em zona rural (Diptera: Culicidae). Rev. Saúde públ., S. Paulo, 24: 394-7, 1990.

RESUMO: As atividades antrópicas levadas a cabo em zona rural têm afetado o comportamento de mosquitos Culex (Culex), motivo pelo qual foi realizada investigação para observar seus abrigos naturais em área de pastagem, margem e interior de matas primitivas ou residuais. Foram escolhidas três localidades com características mesológicas diferenciadas pelo típo de atividade humana, todas situadas na região do Vale do Ribeira, Estado de São Paulo, Brasil. As espécies mais abundantes foram $C x$. mollis $(28,0 \%), C x$. declarator $(25,0 \%), C x$. lygrus $(13,0 \%)$ e $C x$. coronator $(9,6 \%)$. $O$ conjunto $C x$. Bidens $+C x$. dolosus $+C x$. chidesteri, de hábito mais urbanizado, foi capturado em número muito reduzido. Com relação aos ambientes pesquisados, a mata contribuiu com 2.281 indivíduos $(71,4 \%)$, sugerindo ser local de abrigo preferido pelo grupo, exceto para $C x$. quinquefasciatus. Avaliou-se o potencial de domiciliação de cada espécie e suas consequêencias para a população humana.

DESCRITORES: Culex. Ecologia de vetores. Domiciliação. Antropofilia.

\section{INTRODUÇĀO}

Os mosquitos Culicidae pertencentes ao gênero Culex, subgênero Culex, parecem beneficiar-se de alterações que o homem introduz no ambiente. $E$ isto porque, freqüentemente, observa-se sua colonização em ecótopos naturais e artificiais resultantes da atividade humana. Ora, se isto ocorre é porque os indivíduos do grupo não são tão exigentes quanto ao tipo de água utilizada, se limpa, estagnada, poluída ou contaminada. Por outro lado, as formas adultas procuram abrigar-se em locais próximos a seus criadouros ou às fontes de alimentação. Esta característica, quanto mais relacionada com ambiente humano, traduz capacidade da espécie à domiciliação, porém não assegurandolhe a obrigatoriedade de estreito relacionamento alimentar com a população humana. Exceção se faz a Culex quinquefasciatus, por ser espécie bem domiciliada e preferencialmente antropófila (Foratti$\mathrm{ni}^{2}$, 1965). Mesmo que o grau de adaptação desta espécie a torne muito competitiva em ambiente domiciliar, a existência de outros nichos ecológicos vagos certamente tornará possível a domiciliação também de outras populaçõ̂es do grupo. Nesse sentido, é válido investigar, individualmente, o hábito destas porém ressaltando-se a identificação dos abrigos, pós-prandial e de repouso, dentre os múltiplos fatores envolvidos na questão.

\section{MATERIAL E MÉTODO}

As áreas pesquisadas recaíram sobre três localidades, denominadas Fazenda Experimental do Instituto Agronômico de Campinas, Bairro de $\mathrm{Pa}$ riquera-Mirim, ambos no Município de PariqueraAçú, e Fazenda Folha Larga no Município de Cananéia. Todas na Região do Vale do Ribeira, Estado de São Paulo.

Quanto às condições mesológicas dessas localidades, ressaltam aspectos diferenciados devido ao tipo de atividade humana. Na Fazenda Experimental ocorre atividade agricola baseada fundamentalmente em sistema de irrigação que se processa durante todo o ano. Para tanto, instalaramse represas, diques, valas e tabuleiros, com boa disponibilidade de coleções hídricas, as quais estão circundadas por pequenas matas residuais. Pariquera-Mirim tem feições voltadas à pecuária, onde grande variedade de animais domésticos se distribui em pastagem entremeada por matas residuais. $O$ solo ali é irregular e por isso possibilita acúmulo de água de chuvas. Em Folha Larga ocorre atividade agropecuária extremamente rudimentar e o espaço aberto está circundado por floresta primitiva. Nota-se a existência de córrego permanente que atravessa inteiramente 0 pasto. $O$ número de habitações humanas é reduzido e o solo,

* Realizado com o auxílio financeiro da "National Academy of Sciences", USA (Grant n² MVR-3R-2-84-6).

** Departamento de Epidemiologia da Faculdade de Saúde Pública da Universidade de São Paulo - Av. Dr. Amaldo, 715 - 01255 - São Paulo, SP - Brasil. 
afetado pela erosão, cria condições de acúmulo de água das chuvas e conseqüentemente chance para criadouros de mosquitos.

A coleta de culicídeos foi feita em abrigos naturais, ao nível do solo, existentes na área de pastagem, margem e interior da mata. Esses abrigos foram aspirados segundo técnica descrita por Forattini e col. ${ }^{5}$ (1987). Embora não esteja consignada a eficiência da técnica de aspiração mecânica para coleta de mosquito deste grupo, foi a taxa elevada de rendimento para o grupo, obtida nesta investigação que ensejou a oportunidade deste relato. Todas as capturas foram realizadas em horário diurno, preferencialmente das 8 às 11 horas. O ritmo de coleta foi de duas vezes por mês, durante doze meses. Todo o material coletado pelo aspirador foi morto no campo com clorofórmio e adequadamente transportado ao laboratório.

\section{RESULTADOS}

As 24 capturas realizadas de janeiro a dezembro de 1985 renderam o total de 3.193 indivíduos pertencentes ao subgênero $C$ ulex.

A Tabela mostra o correspondente a sete espécies, porém outras foram raramente capturadas como Culex bidens, Culex corniger, Culex nigripalpus, Culex saltanensis, Culex usquatus e Culex sp.
O cálculo da percentagem, aplicado para cada localidade, revelou que $37,3,36,0$ e $26,7 \%$ dos mosquitos foram capturados respectivamente na $\mathrm{Fa}-$ zenda Experimental, Pariquera-Mirim e Folha Larga. Em termos do ambiente aspirado, foi unânime o predomínio do interior da mata sobre as demais, onde o total obtido foi de $2.291(66,5 \%)$ indivíduos. Já o melhor rendimento do aberto (área de pastagem) ocorreu em Pariquera-Mirim, (15,7\%) exemplares. Nota-se ainda o encontro acidental de 4 exemplares de $C x$. quinquefasciatus, porquanto as outras 6 espécies apresentaram abundancia decrescente do ambiente florestal ao aberto.

Levando-se em conta o ritmo mensal das coletas, foi possível determinar a variação estacional do rendimento global para $C x$. coronator, $C x$. declarator, $C x$. lygrus e $C x$. mollis.

\section{COMENTÁRIOS}

Inicialmente há de se considerar que a técnica de coleta em apreço é do tipo busca ativa e dirigida para locais de variada natureza. Portanto, a investigação possibilitará idéia espacial dos abrigos extradomiciliares do grupo, com influência no desenvolvimento do fenômeno de domiciliação. Neste particular, foi observado que esta tendência existe, mas tal potencial é ainda variável entre os diferentes componentes.

\section{TABELA}

Resultado global das coletas de mosquitos $C$ ulex ( $C$ ulex) em abrigos naturais e artificiais de três diferentes localidades da Região do Vale do Ribeira, São Paulo, período de janeiro a dezembro de 1985

\begin{tabular}{|c|c|c|c|c|c|c|c|c|c|c|}
\hline Localidade & $\begin{array}{r}\text { Espécies } \\
\text { Locais }\end{array}$ & $\begin{array}{c}\text { Culex } \\
\text { chidesteri }\end{array}$ & $\begin{array}{l}\text { *Grupo } \\
\text { coronator }\end{array}$ & $\begin{array}{l}\text { Culex } \\
\text { dolosus }\end{array}$ & $\begin{array}{l}\text { Culex } \\
\text { lygrus }\end{array}$ & $\begin{array}{l}\text { Culex } \\
\text { mollis }\end{array}$ & $\begin{array}{c}\text { Culex } \\
\text { declarator }\end{array}$ & $\begin{array}{c}\text { Culex } \\
\text { quinquefasciatus }\end{array}$ & $\begin{array}{l}\text { Culex } \\
\text { sp }\end{array}$ & Total \\
\hline \multirow{4}{*}{ 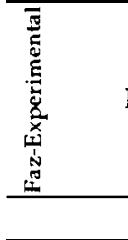 } & Mata & 19 & 79 & 11 & 267 & 197 & 327 & 0 & 86 & 986 \\
\hline & Margem Mata & 8 & 15 & 21 & 9 & 1 & 49 & 0 & 17 & 120 \\
\hline & Aberto & 17 & 10 & 4 & 12 & 1 & 11 & 0 & 31 & 86 \\
\hline & Subtotal & 44 & 104 & 36 & 288 & 199 & 387 & 0 & 134 & 1.192 \\
\hline \multirow{4}{*}{ 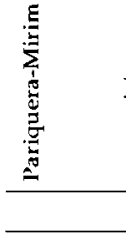 } & Mata & 4 & 23 & 4 & 66 & 154 & 77 & 0 & 223 & 551 \\
\hline & Margem Mata & 4 & 5 & 21 & 1 & 14 & 28 & 0 & 23 & 96 \\
\hline & Aberto & 3 & 115 & 25 & 28 & 72 & 101 & 3 & 81 & 501 \\
\hline & Subtotal & 11 & 143 & 50 & 95 & 240 & 206 & 3 & 327 & 1.148 \\
\hline \multirow{5}{*}{ 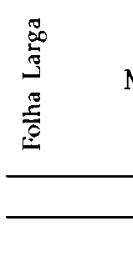 } & Mata & 1 & 32 & 1 & 21 & 404 & 146 & 0 & 139 & 744 \\
\hline & Margem Mata & 1 & 9 & 3 & 1 & 10 & 31 & 0 & 21 & 76 \\
\hline & Aberto & 0 & 6 & 5 & 1 & 19 & 10 & 1 & 64 & 106 \\
\hline & Subtotal & 2 & 47 & 9 & 23 & 433 & 187 & 1 & 224 & 926 \\
\hline & Total & 57 & 294 & 95 & 406 & 872 & 780 & 4 & 685 & 3.193 \\
\hline
\end{tabular}

* inclui $C x$. coronator $+C x$, usquatus 
No que concerne aos mosquitos do subgênero $\mathrm{Cu}$ lex presentes nesta investigação, nota-se que espécies como $C x$. declarator, $C x$. lygrus e $C x$. mollis preservam ainda características selváticas relativas a floresta, quer seja primitiva, residual ou secundária (Tabela). Além disso, está claramente explicitado no Vale do Ribeira o rendimento do local mata, como tendo contribuído com $67,6 \%$ do total capturado, semelhantemente ao encontrado por Oliveira e col.8 (1985), em Jacarepaguá, Estado do Rio de Janeiro, com 63,2\%. São excluídas quase completamente do grupo as espécies $C x$. quinquefasciatus e $C x$. coronator. Forattini e col.5 (1987), avaliando a endofilia de culicídeos na mesma região, verificaram a preferência dos indivíduos do subgênero Culex para abrigos no peridomicilio, enquanto que esta observação, feita através de armadilha CDC, revelou resultado quase nulo (Gomes e col.6, 1987).

Por outro lado, a regularidade do encontro de todas as espécies em abrigos situados do ambiente silvestre ou domicilios evidencia mobilidade elevada do grupo na área estudada, o que poderá sugerir desenvolvimento evolutivo de adaptação aos locais onde o homem mantém atividades. Observaçōes isoladas sobre a preferência hospedeira de $C x$. coronator, $C x$. mollis para aves, no Vale do Ribeira (Forattini e col.4 1987), ou o encontro de $C x$. declarator em vasos de cemitério (Correia e Ramalho' 1959), ao lado das capturas desta e de outras do grupo, em isca humana realizada em Jacarepaguá (Oliveira e col. ${ }^{8}, 1985$ ) são informaçōes que corroboram positivamente com o raciocínio acima.

O conjunto chidesteri+dolosus+bidens não foi expressivo, o que poderá ser entendido pela utilização de abrigos não localizados na área pesquisada ou nível de adaptação a ambientes mais urbanizados. Esta última suspeita vai ao encontro do relato de Forattini e col. ${ }^{3}$ (1973) onde assinalaram, com a tipo de coleta por armadilha New Jersey, a existência de nível de competição acentuada entre este conjunto e $C x$. quinquefasciatus. Mereceria menção também o encontro de proporção igual desta espécie e $C x$. chidesteri em paredes internas de habitações humanas em Jacarepaguá (Oliveira e col. $\left.{ }^{8}, 1985\right)$.
A distribuição sazonal dos resultados obtidos no Vale do Ribeira revela que $C x$. declarator tem ocorrência em todas as estaçōes, fato também observado em Jacarepaguá (Oliveira? , 1984). Porém, naquela regiaao, $C x$. mollis e $C x$. lygrus praticamente alternavam-se com $C x$. declarator nas estações verão-outono e inverno-primavera, respectivamente.

Merece menção particular os resultados de cada localidade, cujos valores numéricos globais não indicaram claramente que fatores individuais eram mais importantes nesta ou naquela localidade. Contudo, a regularidade do rendimento da aspiraçáo em todos os locais de coleta de Pariquera-Mirim poderia ser interpretada como comprovação da existência de condiçбes ecológicas provavelmente mais favorável ao desenvolvimento do fenômeno de domiciliação de mosquitos Culex. Nesse sentido, as condições mesológicas básicas seriam a existência de variados tipos de coleçðes líquidas durante todo - ano, disponibilidade hospedeira relacionada a diferentes tipos de animais, incluindo o homem, matas residuais circundando esta localidade, e diversos artefatos que se prestam a criadouros ou ao repouso e abrigo desses insetos. De uma forma ou de outra, pode-se admitir que haja muitas características ecologicas comuns deste local com a Granja Cabrália, em Jacarepaguá, motivo pelo qual os mosquitos Culex mereceram o atual destaque.

Em conclusão a análise das obsevações ecológicas sobre mosquitos do subgenêro Culex da região do Vale do Ribeira evidenciaram a mata como locais de abrigo preferenciais do grupo. Não obstante, a persistência das características silvestres do grupo, a ocorrência de mobilidade envolvendo as espécies em ambiente intra e extraflorestal, incluindo o domicilio, sugere a viabilidade potencial destas se adaptarem ao ambiente antrópico.

\section{AGRADECIMENTO}

Ao Sr. Daniel Marucci, pelo tratamento automatizado dos dados. 
GOMES, A. de de C. \& FORATTINI, O. P. [ Resting places of mosquitoes Culex (Culex) in rural zones (Diptera: Culicidae)]. Rev. Saúde públ., S. Paulo, 24: 394-7, 1990.

\begin{abstract}
The human activities carried out in rural zones have been affeecting the behavior of mosquitoes of the Culex (Culex) subgenera, which was the reason for undertaking this investigation with a view to registering data on the natural resting places in pastures and on the edge of or within primitive and residual forest areas. Three localities with different mesological conditions, as to type of human activity, all them situated in the Ribeira Valley region of S. Paulo State, Brazil, were chosen. The species most abundantly found were $\mathrm{C} x$. mollis $(28.0 \%), \mathrm{C} x$. declarator $(25.0 \%), \mathrm{Cx}$. lygrus $(13.0 \%)$ and $\mathrm{Cx}$. coronator $(9.6 \%)$. The collection of mosquitoes $C x$. bidens $+C x$. dolosus $+C x$. chidesteri, known to be more urban, was much smaller than that of any other species of the group. With reference to outdoor environments, woodland contributed with 2,281 individuals $(71.4 \%)$ suggesting their preference for this resting place, except for $C x$. quinquefasciatus. Results are evaluated for the determination of the potential domicilation of each species and consequence of the same for the human population.
\end{abstract}

KEYWORDS: Culex. Ecology, vectors. Domiciliation. Anthropophily.

\title{
REFERÊNCIAS BIBLIOGRÁFICAS
}

1. CORREA, R. R. \& RAMALHO, G. R. Culex (Culex) deanae, nova espécie do gênero Culex linaeus, 1758 (Diptera, Culicidae). Rev. Inst. Med. trop. S. Paulo, 1: $141-3,1959$.

2. FORATTINI, O. P. Entomologia médica. São Paulo, Ed. Universidade de São Paulo, 1965. v. 2.

3. FORATTINI, O. P.; ISHIATA, G. K.; RABELLO, E. X.; COTRIM, M. D. Obsevações sobre os mosquitos Culex da cidade de São Paulo. Rev. Saúde públ., S. Paulo, 7: 315-30, 1973.

4. FORATTINI, O. P.; GOMES, A. de C.; NATAL, D.; KAKITANI, I.; MARUCCT, D. Preferências alimentares de mosquitos Culjcidae no Vale do Ribeira, São Paulo, Brasil. Rev. Saúde públ., S. Paulo, 21: 171-87, 1987.

5. FORATTINI, O. P.; GOMES A. de C.; NATAL, D.; KAKITANI, I.; MARUCCI, D. Freqüência domiciliar e endofilia de mosquitos Culicidae no Vale do $\mathrm{Ri}$ beira, Estado de São Paulo, Brasil. Rev. Saúde públ., S. Paulo, 21: 188-92, 1987.
6. GOMES, A. de C.; FORATTINI, O. P.; NATAL, D. Composição e atividade de mosquito Culicidae. Emprego de armaditha CDC no Vale do Ribeira, Estado de São Paulo, Brasil. Rev. Saúde públ., S. Paulo, 21 : 363.70, 1987.

7. OLIVEIRA, L. de R. Alguns aspectos da ecologia dos mosquitos (Diptera: Culicidae) de uma área de planície (Granja Cabrália), em Jacarepaguá, Rio de Janeiro. I- Freqüência comparativa das espécies em diferentes ambientes e métodos de coleta. $\mathrm{Mem}$. Inst. Oswado Cruz, Rio de Janeiro, 79:479-90, 1984.

8. OLIVEIRA, L. de R.; SILVA, T. F.; HEYDEN, R. Alguns aspectos da ecologia dos mosquitos (Diptera: Culicjdae) de uma área de planície (Granja Cabrália), em Jacarepaguá, Rio de Janeiro. II- Freqüência mensal e no ciclo lunar. Mem. Inst. Oswaldo Cruz, Rio de Janeiro, 80: 123-33, 1985.

Recebido para publicação em 20/3/1990 Aprovado para publicaçäo em 21/811990 